\title{
FINANÇAS, CONSUMO E CIRCUITOS DA ECONOMIA URBANA NA CIDADE DE SÃO PAULO
}

\author{
María Laura Silveira*
}

\begin{abstract}
Partindo do novo papel financeiro e organizacional da cidade de São Paulo, buscamos compreender as interferências do circuito superior sobre o circuito inferior. Ambos os circuitos diferenciam-se pelos graus de capital, tecnologia e organização. Existe uma oferta extraordinária de crédito desburocratizado, realizada por instituições financeiras bancárias e não-bancárias, redes, franquias e outlet de eletrodomésticos, roupas e materiais de construção A complexa organização financeira do circuito superior, apoiada nos atuais sistemas técnicos e na propaganda, permite a expansão social e territorial dos seus mercados, evitando capacidades ociosas e invadindo os mercados tradicionalmente pertencentes ao circuito inferior. Ainda que se trate de um fenômeno nacional, sua densidade, na metrópole paulista, é indiscutível, com a maior concentração de estabelecimentos e dinheiro. Criam-se novos nexos de subordinação, e as áreas mais concentradas da metrópole tornam-se localizações necessárias para essas grandes empresas. Aumentam, concomitantemente, o consumo e a pobreza.

PALAVRAS-CHAVE: circuitos da economia urbana, instituições financeiras, oferta de crédito na cidade, oferta de crédito aos pobres, São Paulo.
\end{abstract}

\section{INTRODUÇÃO}

A metrópole é um grande meio de produção material e imaterial, lugar de consumo e nó de comunicações. Para ali convergem resultados contraditórios de um processo de modernização, porque abriga a parcela mais significativa das atividades hegemônicas de produção e controle, com os salários mais altos e, ao mesmo tempo, as mais diversas escalas de renda, incluindo os salários mais baixos de uma nação.

Atividades bancárias e financeiras, comércios, indústrias e serviços modernos, frequentemente orientados para a exportação, constituem o circuito superior. Derivado dele, identificamos uma economia pobre, constituída por atividades de fabricação, comércio e serviços cujo grau de capitalização, tecnologia e organização é relativamente baixo. É o circuito inferior da economia urbana (Santos, 1975).

* Doutora em Geografia Humana pela Universidade de São Paulo. Professora do Departamento de Geografia da Universidade de São Paulo. Pesquisadora do CNPq. Universidade de São Paulo, Faculdade de Filosofia, Letras e Ciências Humanas, Departamento de Geografia. Av. Prof. Lineu Prestes, 338, Cidade Universitária. Cep: 05508-900 - São Paulo - Brasil. laurasil@usp.br
Discutiremos aqui o papel que o sistema financeiro e as novas formas organizacionais de algumas empresas comerciais exercem na consolidação de um moderno circuito superior e suas interferências no circuito inferior da economia urbana. Nos dias de hoje, existe uma oferta extraordinária de crédito de instituições financeiras bancárias e não-bancárias, redes, franquias e outlet de eletrodomésticos, roupas e materiais de construção. Uma profusão de formas de crédito pessoal favorece o aumento do consumo e, simultaneamente, o endividamento, a inadimplência e a insolvência. As novas formas de venda de bens, serviços e inclusive dinheiro estão estreitamente vinculadas às novas configurações do meio construído na cidade de São Paulo, como as localizações em áreas de maior densidade do circuito inferior.

\section{DIVISÕES TERRITORIAIS DO TRABALHOE SUASESCALAS}

Hoje, a divisão territorial do trabalho hegemônica de uma nação edifica-se sobre novas 
variáveis determinantes, isto é, tecnociência, informação e finanças, que permitem às grandes empresas e aos bancos novas escalas e possibilidades de ação. Nos seus diversos segmentos, o Estado torna-se um acelerador ou um freio para tais variáveis, cuja vocação para a convergência é inegável. A técnica informacional tem sido quiçá a mais emblemática, pois permite a integração das demais, isto é, a formação de um verdadeiro sistema técnico com tendência à unicidade. Essa mesma técnica fez possível a circulação de uma dada informação que normatiza a forma de trabalhar e, ao mesmo tempo, possibilita e legitima os grandes volumes de dinheiro especulativo. Por fim, as lógicas próprias desse dinheiro em estado puro que não abandona tal forma por ser a mais rentável - subordinam todas as formas de produção e acumulação. A sofisticação contemporânea dos instrumentos financeiros e sua capilaridade no território revelam um retrato extremamente complexo, que pode ser entendido a partir dessas três unicidades já assinaladas por Milton Santos (1996): unicidade técnica, convergência dos momentos e unicidade do motor.

Todavia o território nacional e a metrópole revelam áreas opacas a tais mandamentos e, por isso, poderiam ser pensados como uma superposição de instrumentos de trabalho, profissões, empregos, normas, formas de produção e circulação. Isso se deve, de um lado, à acumulação de elementos materiais e imateriais pertencentes a vários períodos e, de outro, à desigual capacidade dos agentes para apropriarem-se de elementos contemporâneos e utilizá-los. Desse modo, o meio construído metropolitano abriga todas as divisões territoriais do trabalho e não apenas as modernas, mesmo com profundas segmentações.

No século atual, o circuito superior caracteriza-se pela presença de poderosos agentes financeiros, assim como pelo conteúdo financeiro na política dos demais agentes hegemônicos. Sua porção mais hierárquica está constituída por bancos, fundos de pensão, fundos de investimento, consultorias (Bernardes, 2001) e holdings integrados por empresas industriais, comerciais e de ser- viços avançados (Sassen, 2007). Amiúde, trata-se de grandes firmas que fundam e controlam bancos e instituições financeiras, mas também de grandes bancos que criam e controlam instituições financeiras. É o caso de várias das instituições com presença importante na cidade de São Paulo: BV Financeira do Banco Votorantim, CitiFinancial do Citigroup, Finasa do Bradesco, Fininvest do Unibanco, Ibi da COFRA Holding AG e Redevco, Losango do HSBC, Panamericano do Grupo Silvio Santos e Taií do Itaú (Santos, 2007). O retrato se perfaz com as parcerias entre grandes redes comerciais e grandes grupos bancários e financeiros: Lojas Pernambucanas e ABN AMRO-Real, que foi recentemente comprado pelo grupo Santander, Leroy Merlin e o grupo Fininvest-Unibanco. Além disso, a holding Globex Utilidades S.A., que controla a rede de eletrodomésticos Ponto Frio, é proprietária de 50\% das ações do Banco Investcred Unibanco S.A.

De um modo geral, quando o capital financeiro substitui o capital bancário e o capital comercial, a empresa ganha maior autonomia na busca dos seus objetivos. Isso se agrava quando o governo nacional - ou algum outro nível de governo satisfaz suas demandas e prepara as condições normativas para a produção de sua base material e organizacional.

O poder técnico da grande empresa, alicerçado em novos conteúdos informáticos e de automação, como caixas eletrónicos, cartões e acesso em tempo real aos bancos de dados, completa-se com o poder político, determinado pela acumulação sem relação direta com o tamanho do mercado, pela excessiva financeirização e pela publicidade que mantém o desvio entre custos e preços, permitindo o aumento dos lucros. Em consequência, a situação de oligopólio tende a ser naturalizada.

Dessa maneira, o circuito superior ganha autonomia, mas não independência, pois está unido ao resto da sociedade por uma relação de necessidade. Para ampliar os lucros, seus agentes precisam vender produtos e serviços, aí incluídos os de natureza financeira, aos mais pobres.

Pelo seu baixo grau de tecnologia, capital e 
organização, o circuito inferior, que se desenvolve onde o meio construído está mais degradado, pode oferecer produtos mais simples, essenciais ou supérfluos, criativos ou imitativos a uma população que não tem acesso aos produtos da economia superior. Contudo, nas palavras de Featherstone (1991, p. 47), essa "oferta constante de novos bens, desejáveis por estar na moda, ou a usurpação dos bens marcadores existentes por parte de grupos inferiores" leva o circuito superior a investir em novos bens para manter as distâncias originais.

Entre as empresas menos capitalizadas e tecnificadas, o grau de mortalidade é alto, graças à sua dependência da conjuntura e sua incapacidade de autodefesa diante das alterações bruscas do peso relativo dos fatores de produção. A taxa média de mortalidade das micro e pequenas firmas brasileiras alcançava, em 2004, 31,3\% (Vox Populi, 2004). Como o consumo se mantém em níveis constantes ou crescentes, novas firmas surgem para realizar as mesmas tarefas. Essas firmas concorrem entre si e dependem umas das outras, fornecedoras de bens intermediários ou compradoras de bens finais. A migração de mão-de-obra entre elas é frequente. Cria-se, portanto, uma teia que permite a produção de um pequeno excedente.

Contudo, nos dias de hoje, o crescimento do circuito inferior revela a existência de uma pobreza estrutural, isto é, não marginal nem ocasional, mas uma "produção científica, globalizada e voluntária da pobreza” (Santos, 2000, p. 72), que advém da crescente racionalização da sociedade e do território. O que é mais racional, no processo de tornar-se competitivo, deve ser aplicado, eliminando todo tipo de viscosidades políticas, jurídicas, sociais e culturais. Desse modo, difundem-se sistemas técnicos automatizados para substituírem o trabalho humano, que é sempre considerado mais caro, demandante de pausas e potencialmente criador de conflitos, assim como normas destinadas a reduzir a quantidade de mão-de-obra, ou a transferir à esfera individual um conjunto de condições consideradas anteriormente soluções de civilização. Como assinala Sennet (2006, p. 96), os reformadores do Estado Previdência esperam que o "novo homem" seja seu próprio consultor médico e gestor do seu fundo de pensão, para diminuir a dependência e a responsabilidade pública. $\mathrm{Na}$ medida em que esse processo de racionalização se globaliza, também o fazem suas conseqüências e seus produtos, como a pobreza. Se, no discurso, é considerada como um fato indesejável, na prática, a pobreza é necessária ao funcionamento de um sistema governado por nexos financeiros. Afinal, a divisão do trabalho nascida do neoliberalismo tem sido produtora de pobreza e dívidas sociais. No município de São Paulo, registrou-se, entre 1995 e 2004, uma queda de cerca de 45\% na renda média real dos assalariados no trabalho principal (Fundação SEADE, 2003; DIEESE, 2004). Considerando a mesma série histórica para o município, vemos que a maior perda da renda média real (55\%) corresponde aos trabalhadores autônomos. Tanto os funcionários do setor público como os do setor privado com carteira de trabalho viram decrescer suas rendas em $34,6 \%$ e 44,2\%, respectivamente. Os trabalhadores do chamado setor informal mostram uma leve queda na sua já baixa renda mensal.

Outrossim, se consideramos o período de 1985 a 2005, a taxa de desemprego passou, com sensíveis variações, de 11,4\% a 15,7\%. Em 2003, quando a taxa média da cidade era de $18,7 \%$, na Zona Sul II ${ }^{1}$ alcançava 21,5\%. Os mais pobres tiveram, historicamente, menos acesso às formas modernas de comercialização, que exigiam liquidez ou crédito formal. Sua localização na cidade também reduzia essa acessibilidade. Daí a utilização de circuitos menos modernos de distribuição e seu apelo a formas mais simples, como o crédito informal e o fiado, que não desaparece completamente porque os pobres não param de crescer. Os valesrefeição ganham o uso e o valor do dinheiro vivo. Enquanto isso, o agiota deixa o seu lugar para as instituições financeiras.

${ }^{1}$ Compreende os distritos de Campo Grande, Campo Limpo, Capão Redondo, Cidade Ademar, Cidade Dutra, Grajaú, Jardim Ângela, Jardim São Luís, Marsilac, Parelheiros, Pedreira, Santo Amaro, Capela do Socorro e Vila Andrade (Fundação SEADE, 2003; Santos, 2007). Segundo estimativas do IBGE em 2007, a população total do município de São Paulo (sem a área conurbada) era de 10.886.518 habitantes. 
A cidade pode ser vista, desse modo, como um conjunto indissociável de formas materiais, modernas e antigas, e de formas dominantes e subordinadas de trabalhar e acumular. O papel do poder público não é neutro, pois, a cada reforma material ou normativa visando à modernização, está privilegiando certos graus de capital, tecnologia e organização da economia urbana e certas porções do meio construído.

\section{A INTERFERÊNCIA DO DINHEIRO GLOBALNA CIDADE}

A capilaridade da técnica, da informação e das finanças permite uma expansão social e territorial dos mercados do circuito superior jamais vista, que contribui para evitar tanto a superprodução quanto a capacidade ociosa da indústria, ou ainda o excesso de estoques no comércio, incluindo o problema da obsolescência de certas mercadorias. Mesmo quando algumas grandes firmas se desinteressam por certas parcelas da cidade ou do território, dir-se-ia que o circuito superior não despreza nenhum mercado, ainda mais quando nele pode introduzir sofisticados instrumentos financeiros. A venda de bens de consumo banal, como roupas, materiais de construção, móveis e eletrodomésticos a crédito, mas também de seguros pessoais, residenciais e odontológicos, assim como a concessão de empréstimo pessoal, se orientam a satisfazer - e a criar - uma demanda das classes sociais que antes se vinculavam, pela produção ou pelo consumo, ao circuito inferior. Isso sucede, fundamentalmente, em áreas da cidade que, até há pouco tempo, não granjeavam o circuito superior. Tal mercado pode ser caracterizado como uma constelação de indivíduos e famílias de baixa renda que buscam satisfazer necessidades consuntivas e produtivas, em centralidades de alta densidade, e que, graças ao seu importante número, tornam-se um volume total significativo. Por exemplo, Casas Bahia (venda de eletrodomésticos e móveis) tem 99 lojas na cidade de São Paulo, das quais 21 estão no centro antigo. Sua topologia alcança distritos das Zonas Leste e Sul e, ainda, da Zona Norte, ${ }^{2}$ nos quais a renda média do responsável da família é inferior a $R \$ 700,00$ (menos de dois salários mínimos). Alguns desses distritos da Zona Sul, como Jardim São Luís, Capão Redondo, Cidade Ademar, Vila Andrade, Marsilac, Grajaú e Jardim Ângela mostravam taxas de desemprego superiores a 20\%. Nesses dois últimos distritos, a empresa possuía duas lojas em cada um. Também áreas periféricas, como Cidade Tiradentes (extremo oriental do município), com alto desemprego, abriga uma loja de Casas Bahia. ${ }^{3}$ As instituições financeiras espalham-se praticamente por todo o município, ${ }^{4}$ revelando, ao mesmo tempo, uma forte presença no centro antigo da cidade, mas também onde a renda do responsável da família é menor, como a Zona Leste e a Zona Norte. ${ }^{5}$ Mais da metade dos entrevistados havia realizado a operação numa agência próxima ao local de trabalho e, geralmente, no horário do almoço. Horários mais estendidos e flexíveis do que os bancários não são um dado menor, já que as financeiras podem produzir, em certos momentos do dia, uma situação de oligopólio ou monopólio, sobretudo quando se trata de indivíduos que precisam prementemente saldar uma dívida anterior. Os produtos que essas firmas oferecem são fundamentalmente créditos e empréstimos pessoais, financiamento de bens e serviços, sobretudo de automóveis, cartões de crédito e seguros diversos que incluem, como no caso de Ibi, seguro odontológico.

2 Trata-se dos distritos Vila Curuca e Iguatemi na Zona Leste; Grajaú, Jardim Angela, Parelheiros, Pedreira, Marsilac e Cidade Dutra na Zona Sul e Brasilândia na Zona Norte.

Enquanto Lojas Pernambucanas - rede comercial de roupa e eletrodomésticos - possui 32 estabelecimentos em São Paulo, Ponto Frio (eletrodomésticos, móveis e informática) soma 37 estabelecimentos e Leroy Merlin (materiais de construção e lar) tem 5 estabelecimentos e optou por localizações de fácil acesso por automóvel como as avenidas importantes e as marginais. Lojas Marisa (roupa e acessórios pessoais) tem atualmente 31 lojas, das quais 12 estão em shopping-centers, e acaba de receber um crédito do BNDES para ampliar sua topologia de estabelecimentos. As baixas taxas de juros desse crédito contrastam com os juros cobrados dos clientes das lojas.

${ }^{4}$ As maiores concentracões de financeiras (entre 9 e 28 filiais) estão nos distritos Sé, República, Sanțana, Tatuapé, Penha, Itaquera, Vila Prudente, Praça de Árvore, Itaim Bibi, Santo Amaro, Grajaú, Campo Limpo, Lapa e Pinheiros.

Itaim Paulista, Vila Curuçá, Lajeado, Guianases na Zona Leste e Brasilândia e Pirituba na Zona Norte. 
De modo geral, tanto as empresas comerciais como as financeiras instalam-se nas áreas de diversidade da metrópole (Silveira, 2004), isto é, em lugares de importante circulação, nos quais os circuitos de diversos ramos se entrecruzam e criam um mercado segmentado. Tratar-se-ia de pontos eáreas densos da divisão do trabalho que, em geral, são áreas degradadas, como numerosas porções do centro antigo, Largo Treze em Santo Amaro, Largo da Batata em Pinheiros, Rua Nossa Senhora da Lapa, Itaquera. Contudo, financeiras não faltam nas áreas de especialização (Silveira, 2004) ou nas proximidades delas, isto é, onde encontramos a coexistência de circuitos de um mesmo ramo de atividade. Nessas condições, novas fontes de riqueza e novas razões de pobreza instalam-se na metrópole.

Não deixa de ser um dado novo tal resposta do circuito superior às demandas banais da população pobre em áreas mais degradadas da cidade. Essa expansão da produção e da distribuição em escala metropolitana é acompanhada, numa relação de necessidade, do aumento da capacidade de organização macroeconômica do território. Novos nodos podem ser identificados. Por exemplo, Casas Bahia tem 7 centros de distribuição e 7 entrepostos nas regiões Sudeste, Sul e Centro-Oeste, dos quais partem mais de 900 mil entregas por mês, com mais de 1.400 veículos próprios, para seus 560 estabelecimentos e 26 milhões de clientes em 10 Estados da Federação: São Paulo, Rio de Janeiro, Espírito Santo, Minas Gerais, Mato Grosso, Mato Grosso do Sul, Goiás, Paraná, Santa Catarina e Rio Grande do Sul, além do Distrito Federal. Em dias comemorativos, as entregas alcançam 1,2 milhões. A receita dessa empresa, no ano fiscal de 2006-2007, foi de US $\$ 4,8$ bilhões, e o número de créditos concedidos foi de 15,2 milhões. Como outras firmas, Casas Bahia criou um cartão com o qual o cliente pode financiar suas compras.

Instituições como ASB Financeira, Banco Cacique, BV Financeira, CitiFinancial, Crefisa, Finasa, Fininvest, GE Money, Ibi, Losango, Olé, Panamericano e Taií apresentam densas topologias no território nacional. Por exemplo, Finasa (antiga Zombi comprada pelo Bradesco) tem 317 agênci- as, das quais 53 estão no município de São Paulo (cerca de 17\%), ao tempo que Losango (HSBC) tem 22 dos seus estabelecimentos brasileiros na cidade de São Paulo (7,3\%), Fininvest (Unibanco) tem 295 agências no Brasil, das quais 47 (16\%) na cidade. CitiFinancial do CitiGroup conta com 77 agências no país, das quais 24 (31,2\%) estão na capital paulista. As instituições que revelam uma geometria mais ampla e densa no território nacional são as vinculadas a bancos.

Cada empresa, cada ramo de atividade, produz uma lógica territorial cuja manifestação mais visível é uma topologia, isto é, esse conjunto de pontos e áreas de interesse para a operação da empresa que, certamente, ultrapassa a própria firma e se projeta sobre outros atores sociais. São os pontos essenciais ao exercício da atividade de um circuito superior, que revela sua capacidade de macro-organizar o território nacional.

Causa e consequência dessa expansão territorial e econômica das instituições financeiras, o crédito rápido, formal e liberado de exigências burocráticas torna-se onipresente. O crédito bancário institucional foi historicamente burocrático, deixando extensas porções do mercado aos agiotas, isto é, a um crédito pessoal não-institucional, caro, fácil e direto. Os agentes do circuito inferior, que precisavam de liquidez, tornavam-se uma clientela cativa e dependente, e o agiota era um traço de união na economia urbana. As instituições financeiras bancárias e não-bancárias passam a cumprir esse papel. Podemos dizer que, hoje, o circuito superior reconhece a importância de desburocratizar o crédito, para estender suas oportunidades de lucro e, assim, os requisitos exigidos são mínimos. ${ }^{6}$ Todavia o custo desse crédito é extremamente alto, com taxas de juros que oscilam entre $5 \%$ e $13 \%$ ao mês. Constituído por baixo capital fixo, o circuito inferior é amiúde impingido a aumentar seu capital de giro, por meio de um crédito dessa natureza, ainda mais porque muitos desses atores trabalham como pessoa física e não como pessoa jurídica. $\mathrm{O}$ ${ }^{6}$ Em geral, os requisitos exigidos são: carteira de identidavante de residência e de renda. 
spread bancário pode ser o dobro em um caso ou em outro (25\% e 57\% em 2005).

Como nas redes Leroy Merlin e Ponto Frio, nas Lojas Marisa a concessão de cartões tampouco é burocrática, e seu destino é o financiamento de roupas, assim como a aquisição de produtos financeiros, notadamente os seguros. A participação das vendas a prazo no volume total das vendas tem aumentado, representando, em 2007, mais de $21 \%$. A política da empresa buscou priorizar as vendas financiadas a prazo, estimulando a emigração dos clientes de um plano para outro. ${ }^{7}$ Dessa forma, a receita com juros sobre vendas a prazo aumentou de R\$ 20,7 milhões em 2006 para R \$ 77 milhões em 2007. Essa é uma das situações nas quais o capital financeiro substitui o capital comercial e, assim, a empresa é mais autônoma para obter seus lucros pela via de mecanismos financeiros, ainda quando isso signifique, por exemplo, vender menos mercadorias materiais. Gradativamente, a empresa comercial ganha o rosto de uma financeira.

Ciência e técnica participam na produção de cálculos, estimativas, horizontes, políticas de mercado, topologias de agências. Assim, agentes e lugares que não eram atraentes para a concessão de créditos ganham hoje novo status, e a propaganda não deixa dúvidas sobre as novas coerências construídas pelos discursos mercantis. Recentemente, boa parte do crédito pessoal tem sido dirigida aos aposentados e pensionados do INSS e, ainda que as demandas individuais sejam baixas, a grande quantidade de indivíduos acaba por constituir um mercado interessante. Elo final de um embrionário Estado previdenciário, os aposentados e pensionados tornam-se cobiçados por instituições financeiras como ASB Financeira, Banco Cacique, Crefisa, GE Money e Panamericano. ${ }^{8}$

7 A empresa incentivou a migração dos clientes de um plano de 5 parcelas sem juros para outro que aumentava o número de parcelas e embutia uma taxa de juros. A fórmula para conseguir tal resultado foi aumentar as parcelas do primeiro plano, de modo a excluir uma boa parte dos seus clientes que não podiam enfrentar essas obrigações mensais.

${ }^{8}$ Ainda menos exigentes em documentação inicial, essas sociedades de crédito encontram nos aposentados uma garantia, graças à regularidade do seu salário. A propa-
Hoje, um denominador comum das políticas dessas empresas comerciais e financeiras é a orientação dos seus produtos para as camadas mais baixas da sociedade. Havendo descoberto os importantes volumes totais do consumo das denominadas classes C, D e E, que, por outra parte, ajudam a criar, as empresas diminuem os umbrais mínimos de renda dos seus clientes. ${ }^{9}$

Há alguns anos, era impensável que os desempregados fossem interessantes para o mercado formal de crédito. Apesar da intensa propaganda e da redução de exigências burocráticas tanto no financiamento de objetos como na concessão de créditos pessoais e na contratação de seguros, as firmas não descuidam a pesquisa dos clientes potenciais. ${ }^{10}$ Quando se trata da modalidade de desconto na folha de pagamentos, evidentemente o risco de insolvência é menor.

Outro elemento organizacional que permite aumentar o grau e a eficiência da interferência do circuito superior nas camadas mais pobres da população urbana é a associação entre instituições financeiras e grandes redes comerciais. Situações como essas observam-se entre: Taií, Lojas Americanas e Pão-de-Açúcar; Panamericano e Telha Norte; Ibi e C\&A; Fininvest, Leroy Merlin, Makro e Sonda; Finasa e Casas Bahia, entre outras.

De alguma forma, as sociedades de crédito ocuparam os alveólos do sistema bancário público

ganda oral, realizada nas proximidades das agências pelos funcionários, propõe aos jovens que, para obter facilmente o dinheiro, os créditos sejam contratados pelos seus avós, aposentados do INSS.

${ }^{9}$ Uma firma como Leroy Merlin estabelece um umbral mínimo de R\$ 200 para entregar seu cartão (aproximadamente a metade de um salário mínimo), ao passo que uma instituição financeira como Ibi declara que seus clientes têm renda média de $\mathrm{R} \$ 400$. As entrevistas no centro da cidade permitiram esboçar os perfís dos agentes que recorrem ao crédito pessoal: atendentes de lojas e ambulantes, costureiras e sastres, marceneiros, mecânicos, policiais e vigias particulares, ascensoristas e porteiros, office-boys, cabeleireiros, tapeceiros, chaveiros, encadernadores, desempregados e aposentados, cujas rendas mensais variam entre R\$ 400 e R\$ 3.000 (Santos, 2007).

${ }^{10} \mathrm{Um}$ controle importante antecede o contrato e é realizado pela central de risco da empresa. Alí são reunidas as informações pessoais e financeiras dos clientes a partir dos serviços de proteção ao crédito (SPC e SERASA). Após tais procedimentos, decide-se a soma que será objeto do crédito e, mais tarde, a fiscalização torna-se ferrenha, a partir de um departamento específico da empresa ou de um serviço contratado, que envia cartas, e-mails, realiza telefonemas e, inclusive, chega a ir à casa do cliente. 
e privado, que revelavam uma defasagem entre, de um lado, a situação de desemprego e a falta de emprego formal e, de outro, a necessidade de dinheiro líquido. Dir-se-ia que a expansão bancária foi mais lenta, apesar de que novos eventos, como os correspondentes bancários, chegam hoje à população que não tinha conta corrente (Dias, 2006; Contel, 2006).

O crédito tem aumentado significativamente nos últimos anos. Entre 1995 e 2005, as operações de crédito do sistema financeiro nacional se triplicaram. Todavia foram as operações de crédito de pessoas físicas que tiveram um crescimento extraordinário (cerca de 15 vezes numa década). Ainda que boa parte das instituições financeiras seja anterior à década de 1990, o número de agências, de novas instituições financeiras e o volume de dinheiro emprestado cresceram significativamente a partir do Plano Real em 1994. A partir da estabilização da moeda, houve uma explosão do consumo financiado de bens duráveis como geladeiras, fogões, televisões e, inclusive, automóveis, mas também de bens imateriais. Todas as redes comerciais e instituições financeiras às quais temos nos referido conheceram, nos últimos anos, um significativo crescimento no número de estabelecimentos comerciais, vendas, clientes, cartões, serviços, produtos, empréstimos, assim como uma sofisticação na logística e organização. Além disso, deve ser assinalado o processo de aquisições e fusões, ${ }^{11}$ de obtenção de créditos públicos e outras políticas que favoreceram a busca de liquidez e o consumo.

O problema é que tal fortalecimento dos agentes hegemônicos termina por repercutir no circuito inferior da economia, na medida em que este perde mercados. Os problemas de acessibilidade pela deficiência do transporte encontram um fator compensador no desenvolvimento de sub-

${ }^{11}$ A rede Ponto Frio, que integra a holding Globex Utilidades S.A., foi realizando aquisições para tornar-se presente nos Estados que participam mais ativamente na economia nacional internacionalizada. É uma prova do papel dos conteúdos do território no valor e funções de uma empresa. No grupo controlador da Ponto Frio estão, junto à Globex Utilidades S.A. que é de capital aberto, as holdings Keene Investments Corp., Phillimore Holdings Ltd., Blue Springs Holdings Ltd. e Tamarac Invesments Corp. centralidades, verdadeiros abrigos para o circuito inferior, mas também para o circuito superior marginal. Como produto de uma certa imobilidade, formam-se áreas de diversidade que, pela sua densidade e dinamismo, terminam sendo atrativas ao circuito superior. Quando as firmas comerciais tornam-se financeiras e buscam orientar-se em direção às camadas mais baixas, as pessoas consomem mais, porém têm menos oportunidades para produzir. O consumo dos pobres passa a realizarse crescentemente no circuito superior, embora sua localização revele que se trata de lugares característicos do circuito inferior.

\section{DA OFERTA DESENFREADA À PROCURA DESENFREADA DE CRÉDITO NA CIDADE}

Graças ao crédito, sobretudo quando está livre de burocracia, a difusão do consumo encontra menos impedimentos sociais. Graças à tecnificação da circulação, a difusão do consumo encontra menos impedimentos territoriais.

Em 2005, cerca da metade do volume de dinheiro emprestado no Brasil correspondeu a créditos a indivíduos. Esse tipo de crédito tem crescido mais do que o crédito para empresas e autarquias estatais (Contel, 2006, p. 273). Por outra parte, do total de crédito a pessoas físicas em 2005, 49,2\% dos créditos eram inferiores a R\$ 5.000. O crédito pessoal no Brasil aumentou significativamente, passando de $\mathrm{R} \$ 16,3$ bilhões em 2000 a R $\$ 75,6$ bilhões em 2005, o que representa um aumento de 4,6 vezes. Sem dúvida, essa situação tem profundas diferenças territoriais, pois, na agência da Rua São Bento, no centro antigo da cidade de São Paulo, o Banco Cacique concede R\$ 2 milhões por mês em créditos pessoais, enquanto, num bairro da Zona Oeste, como Pinheiros, Finasa declarou que seu volume de operações alcança R\$ 200 mil por mês.

Nas entrevistas, os motivos indicados para escolher a empresa foram, em ordem decrescente: menor taxa de juros, menos burocracia, ter conta corrente no banco ao qual a financeira está vincu- 
lada, reunir ao mesmo tempo a menor taxa de juros e a menor burocracia. Boa parte desses atores já tinha dívida bancária, revelando que a idéia de falta de bancarização da população mais pobre não parece corresponder completamente à realidade da metrópole paulista. Há uma exacerbação da possibilidade de se obter dinheiro adiantado que, para a metade dos entrevistados, permite o pagamento das dívidas atrasadas. Para alguns, trata-se de dívidas em concessionárias de automóveis ou em redes de eletrodomésticos e móveis. Para outros, trata-se simplesmente de pagar contas de eletricidade, água, telefone, ou mesmo comprar alimentos e, assim, evitar a condição de inadimplente nos órgãos de proteção ao crédito. Entra-se numa dívida para sair de outra e, desse modo, não se rompe o círculo vicioso do empobrecimento. Tecem-se novos nexos entre empresas do circuito superior e trabalhadores do circuito inferior, cuja manifestação mais visível é o consumo de bens, serviços e dinheiro, sob forte relação de dependência com tais firmas. Em consequência, aumenta a distância entre o circuito superior, portador de mais lucros e menos capacidades ociosas, e o circuito inferior, cada dia mais pobre e endividado. Contudo, o endividamento cresce e atravessa as classes sociais. Mais de $55 \%$ dos habitantes da cidade de São Paulo estão endividados e, desse grupo, $37,3 \%$ atrasaram o pagamento das dívidas.

Ainda que uma característica metropolitana seja a tendência à anulação de sazonalidades graças à superposição de divisões territoriais do trabalho, o domínio das finanças termina por impor novos calendários. Se, nas redes de roupas, eletrodomésticos e móveis, os picos de venda se dão em datas comemorativas, como dia das mães ou Natal, a maior demanda de crédito pessoal nas financeiras corresponde a momentos posteriores a tais datas, em função das dívidas assumidas. A intensa propaganda de final de ano, que explora o fato de receber o décimo terceiro salário, faz aumentar as despesas e, alguns dias depois, cresce a demanda por crédito nas financeiras.

Os serviços financeiros oferecidos pelas grandes redes comerciais, como empréstimos, cré- ditos e seguros, constituem parte significativa dos seus lucros. Em 2005, tais serviços financeiros representavam a metade dos lucros da empresa Casas Bahia. Segundo informações corporativas, a Ponto Frio teve um aumento na sua receita com serviços - especialmente recarga de celular, seguro de celular e seguro residencial - que significou $43 \%$ entre 2006 e 2007.

Tanto para oferecer serviços banais como serviços qualificados, as firmas assinam contratos com técnicos e profissionais antes autônomos, tornando-os mais uma peça da sua engrenagem. Estes não podem concorrer com os preços das grandes redes comerciais, bancos e empresas seguradoras que oferecem serviços de manutenção de moradias. Desse modo, diminui o mercado para os técnicos e "artesãos" que trabalham de forma autônoma ou em pequenas empresas que reunem profissões diversas. É também o caso dos tapeceiros e dos serviços de conserto de eletrodomésticos e celulares. Observa-se, então, uma capilaridade das empresas para cima mas, igualmente, para baixo, como no caso do seguro odontológico, serviço do qual é desprovida a maior parte da população.

A falta de acesso aos bens de direito universal aumenta, certamente, a necessidade de liquidez. Se a população mais pobre não tem assistência médica e odontológica suficiente pela via do serviço público, ela precisará de mais dinheiro para pagar pelo serviço no mercado. Em consequência, o aumento da demanda por crédito desburocratizado é também diretamente proporcional à redução da oferta de bens e serviços universais. Quanto menos assistidos pelo Estado, os pobres vêem crescer suas necessidades insatisfeitas e precisam de mais dinheiro para sobreviver.

Todos esses eventos contribuem para o endividamento, a inadimplência e, frequentemente, a insolvência. Eis a armadilha. A devolução dos empréstimos, ritmados por taxas leoninas, não pode ser realizada a partir dos baixos lucros obtidos pelo circuito inferior e seus pequenos capitais fixos, ou pelos baixos salários. É uma velocidade que o circuito inferior não pode acompanhar, ainda que, para tentá-lo, seja extremamente dinâmi- 
co, migrando de ramo e atividade no intuito de alcançar um excedente mais alto.

Infelizmente, esse não é o único problema grave. $\mathrm{O}$ aumento do consumo fora do circuito inferior acaba rebatendo neste, pois é uma demanda subtraída das suas pequenas empresas. Sem capacidade para comandar as molas do atual sistema financeiro, o pequeno e médio comércio não pode oferecer um financiamento interessante, tampouco programas de fidelidade e muito menos produzir o convencimento a partir de uma eficiente propaganda. Para as firmas de comércio e conserto do setor informal, ${ }^{12}$ as principais dificuldades encontradas, nos últimos doze meses antes do questionário do IBGE (2002-2003), têm sido predominantemente vinculadas ao mercado e às finanças: $21,7 \%$ das respostas foram falta de clientes, $21,5 \%$ alta concorrência, $19,5 \%$ baixo lucro, $13,4 \%$ falta de capital próprio. A falta de crédito foi apontada em $8,8 \%$ das respostas.

Entre outras, a internacionalização da economia e do território é uma das grandes causas dessas dificuldades: por um lado, uma forte abertura às importações de todo tipo mas, de outro lado, uma alta concentração do mercado varejista interno, protagonizada por grandes empresas transformadas em financeiras, que vivem uma importante transnacionalização dos seus capitais. Quando o consumo interno, seja de eletrodomésticos e móveis, seja de dinheiro ou seguros, é comandado por um punhado de empresas internacionais ou nacionais, pode crescer, mas não significa que se fortaleça o mercado interno. Em definitivo, o que se internacionaliza é o mercado interno, diminuindo as oportunidades de produção dos que não têm poder. Todos são dados de uma nova aceleração, que é um vetor perturbador também trans-

${ }^{12}$ Insistimos no fato de não haver uma associação direta entre circuito inferior e setor informal, pois, apesar da longa discussão sobre o critério para reconhecer esse último, a questão da tributação parece sempre predominar. Não é nossa intenção entrar nesse debate nesta ocasião, pois já o fizemos em outra oportunidade (Silveira, 2008), mas apenas frisar que o critério que identifica o circuito inferior é o baixo grau de tecnologia, capital e organização, e isso não obrigatoriamente coincide com a falta de tributação. No entanto, como se trata das estatísticas disponíveis, adotaremos aqui os interessantes dados sobre o setor informal levantados pelo IBGE em 2003, os quais também consideram outras variáveis. mitido horizontalmente no circuito inferior. A necessidade de obter lucros rapidamente, em atividades e com capitais que não o permitem, pode instalar relações implacáveis ou autorizar formas de violência, com o risco de rasgar a teia do circuito inferior. Não deixa de ser a imposição, no circuito inferior, de uma racionalidade hegemônica.

\section{APROPRIAÇÃO DO DINHEIRO SOCIALE VALORIZAÇÃO DESIGUAL DO MEIO CONSTRUÍDO: algumas premissas}

A difusão da técnica na metrópole, sempre de modo desigual e inacabado, permite participar das promessas de consumo feitas pela propaganda. Todavia, a norma não se faz esperar e ganha potência para regular um mercado em expansão. Desse modo, a via contratual atravessa as relações e mascara, com um direito específico, a força desigual das grandes empresas e dos indivíduos ansiosos por consumir ainda que sem liquidez. É a sociedade de contratos que permite, ao mesmo tempo, a proteção da empresa e deixa a cidadania sem defesa. O papel do poder público é bastante residual, pois o que predomina são as relações mercantís.

Ao naturalizarem-se as relações mercantís, esvazia-se a idéia de que os bens e serviços que são de interesse comum deveriam ser reconhecidos como direitos legítimos e sua distribuição obrigatoriamente universal. Quando a oferta pública não alcança todas as pessoas nem todos os lugares tende a instalar-se e a crescer a oferta mercantil, encarnando uma resposta segmentada e parcial a esses reclamos. Essa é a lógica do mercado, isto é, alocar-se em áreas ou em camadas sociais onde a demanda já existe ou tem grandes perspectivas de desenvolver-se. Contudo, a demanda que interessa é uma demanda solvável. Daí que certos lugares e camadas sociais não sejam, a priori, interessantes, a menos que a solvência seja assegurada pelo crédito sob suas diferentes formas. Desse modo, surgem fragmentações socioespaciais e, em consequência, curto-circuitos no exercício da cidadania. 
A atual arquitetura político-administrativa fortalece a idéa de que à escala municipal de governo cabem mormente as responsabilidades do meio construído, enquanto à escala federal cabe a formulação de políticas macroeconômicas raramente discutidas sobre bases territoriais. Assim, os eventos próprios da globalização das finanças batem às portas da cidade, agravando as brutais disparidades de renda e a fragmentação do meio construído, ainda que tal interface dificilmente se ponha como uma questão para o poder público. Aceita-se o custo exorbitante do dinheiro emprestado, o endividamento crônico como forma de vida social e a definição de insolvência enunciada pelas grandes firmas.

Não ignoramos a existência de políticas de crédito público, mas é evidente a falta de informação, que se acompanha do excesso de propaganda privada e sua ação de convencimento sobre certos consumos. O Banco do Povo e a Caixa Econômica Federal oferecem políticas de crédito para pequenos empresários, mas parece haver certa incapacidade de difundir a informação. O comando e o uso da informação na esfera do Estado não parece tão eficiente como no seio do circuito superior. Tampouco podemos esquecer as políticas internacionais de microcrédito, cuja dinâmica e natureza é diversa. Em boa parte das situações, trata-se de um complexo diálogo em escala internacional, mediado pela presença de ONGs e com a presença de bancos globais. É importante destacar que parte da propaganda das instituições financeiras analisadas explota a idéia de microcrédito, sustentando-se na imagem internacional dessas políticas e ocultando as altas taxas de juros.

A voracidade do circuito superior conduziu a múltiplas e ainda pouco conhecidas formas de dominação da economia urbana pobre. Com a crescente financeirização da sociedade, as sinapses entre ambos os circuitos aumentam significativamente, e certos nexos modernos criam perturbações na vida social dos mais pobres. Essa é a oposição dialética que existe entre ambos circuitos. Nenhum deles pode ter autonomia de significado, porque não tem autonomia de existência. Ambos são opostos e complementares mas, para o circui- to inferior, a complementaridade ganha a forma de dominação.

A metrópole poderia ser entendida como a arena dos atores com existências concretas, onde não apenas se assegure o consumo mas também, e sobretudo, se criem as condições de produção, de modo que a velocidade não seja o princípio implacável que leva ao endividamento e à eliminação de produtos que não sejam globalizados. A construção de um projeto coletivo de sociedade aconselhar-nos-ia a reconhecer a pobreza menos como um resultado indesejado e mais como uma dívida social resultante de um processo produtor de formas de exclusão.

(Recebido para publicação em novembro de 2008) (Aceito em abril de 2009)

\section{REFERÊNCIAS}

BERNARDES, Adriana. A nova divisão territorial do trabalho brasileira e a produção de informações na cidade de São Paulo (as empresas de consultoria). In: SANTOS, Milton; SILVEIRA, María Laura. O Brasil: território e sociedade no início do século XXI. Rio de Janeiro: Record, 2001. p. 413-432.

CONTEL, Fabio Betioli. Território e finanças: técnicas, normas e topologias bancárias no Brasil. 2006. Tese (Doutorado em Geografía) - Departamento de Geografia, Universidade de São Paulo, 2006.

DIAS, Leila Christina. Por que os bancos são o melhor negócio no país? Hegemonia financeira e geografia das redes bancárias. In: ALBUQUERQUE, Edu Silvestre (Ed.) Que país é esse? pensando o Brasil contemporâneo. São Paulo: Globo, 2006. p. 27-62.

DIEESE. Pesquisa de Emprego e Desemprego. São Paulo, 2004.

FEATHERSTONE, Mike. Cultura de consumo y posmodernismo. Buenos Aires: Amorrortu, 1991.

FUNDAÇÃO SEADE. Anuário Estatístico de São Paulo 2003.

IBGE. Coordenação de Serviços e Comércio. As micro e pequenas empresas comerciais e de serviços no Brasil 2001. Rio de Janeiro, 2003. (Estudos e pesquisas, informação econômica, n. 1)

. Diretoria de Pesquisas. Coordenação de Serviços e Comércio. Pesquisa Anual de Comércio 2004-2005.

Estatística do Cadastro Central de Empresas 2005.

SANTOS, Milton L'espace partagé. Les deux circuits de l'économie urbaine des pays sous-développés. Paris: M.Th. Génin/Librairies Techniques, 1975.

A natureza do espaço. Técnica e tempo. Razão e emoçã̃o. São Paulo: Hucitec. 1996. 
Por uma outra globalização. Do pensamento único à consciência universal. Rio de Janeiro: Record, 2000.

SANTOS, Kauê Lopes dos. Uma financeirização da pobreza? O sistema financeiro e sua capilaridade no circuito inferior da economia urbana na cidade de São Paulo. 2007. Monografia. (Graduação em Geografia) - Departamento de Geografia/ Universidade de São Paulo, 2007.

SASSEN, Saskia. El reposicionamiento de las ciudades y regiones urbanas en una economía global: ampliando las opciones de política y gobernanza. Revista EURE, Santiago de Chile, v. 33, n. 100, p. 9-34, 2007.

SENNET, Richard. A cultura do novo capitalismo. Rio de Janeiro: Record, 2006.
SILVEIRA, María Laura. Globalización y circuitos de la economía urbana en ciudades brasileñas. Cuadernos del CENDES, Caracas, v. 3, n. 57, p. 1-21, 2004.

. Metrópoles do terceiro mundo: da história ao método, do método à história. In: SILVA, Catia Antonia CAMPOS, Andrelino. Metrópoles em mutação. Dinâmicas territoriais, relações de poder e vida coletiva. Rio de Janeiro: Revan/FAPERJ, 2008. p. 17-35.

VOX POPULI. Fatores condicionantes e taxa de mortalidade das MPE 2004. Goiânia: Sebrae/Goiais Gerais, 2007. v. 2 . 


\section{FINANCES, CONSUMPTION AND CIRCUITS OF URBAN ECONOMY IN THE CITY OF SÃO PAULO}

\author{
María Laura Silveira
}

Beginning with the new financial and organizational role of the city of São Paulo, we tried to understand the interferences of the upper circuit on the lower circuit. Both circuits differ by their degrees of capital, technology and organization. There is an extraordinary offer of de-burocratized credit, given by banking and other financial institutions, appliances, clothes and construction materials chains, franchises and outlets. The complex financial organization of the upper circuit, supported by the current advertising and technical systems, it allows the social and territorial expansion of their markets, avoiding idle capacities and invading the markets traditionally belonging to the lower circuit. New subordination connections are created, and the most concentrated areas of the metropolis become necessary locations for those big companies. Consumption and poverty increase simultaneously. Although this is a national phenomenon, its density, in São Paulo, is unquestionable, with the largest concentration of establishments and money.

Keywords: circuits of urban economy, financial institutions, credit offers in the city, credit offers to the poor, São Paulo.

\section{FINANCES, CONSOMMATION ET CIRCUITS DE L'ÉCONOMIE URBAINE DANS LA VILLE DE SÃO PAULO}

\author{
María Laura Silveira
}

Le nouveau rôle financier et organisationnel de la ville de Sao Paulo est la base de notre recherche pour comprendre les interférences du circuit supérieur sur le circuit inférieur. La différence entre les deux se fait en fonction du degré de capital, de technologie et d'organisation. Il existe une offre extraordinaire de crédit débureaucratisé, provenant d'institutions financières bancaires et non bancaires, de réseaux, de franchisings et d'outlet d'électroménagers, de vêtements et de matériel de construction. Lorganisation financière complexe du circuit supérieur, s'appuyant sur les systèmes techniques actuels et sur la propagande, permet l'expansion sociale et territoriale de leurs marchés en évitant l'oisiveté de la main-d'oeuvre et en envahissant les marchés qui appartiennent traditionnellement au circuit inférieur. Même s'il s'agit d'un phénomène national, la densité atteinte dans la ville de Sao Paulo est indiscutable puisque c'est là qu'existe la plus grande concentration d'établissements et d'argent. De nouveaux axes de subordination se créent et les régions les plus concentrées de la métropole deviennent des lieux nécessaires pour ces grandes entreprises. La consommation et la pauvreté augmentent en même temps.

Mots-CLÉs: circuits de l'économie urbaine, institutions financières, offre de crédit dans les villes, l'accès au crédit pour les pauvres, Sao Paulo.

María Laura Silveira - Doutora em Geografia Humana pela Universidade de São Paulo. Professora do Departamento de Geografia da Universidade de São Paulo. Pesquisadora do CNPq na área de "Uso corporativo do território, metrópoles e circuitos da economia urbana no Brasil”. Suas mais recentes publicações são: O Brasil: território e sociedade no início do século XXI (coautora com M. Santos) (2001); Argentina: território e globalização (2003) e Continente em chamas: globalização e território na América Latina (Org., 2005), Metrópoles brasileñas: un análisis de los circuitos de la economía urbana (Eure, 2007, v.33I, n.100). 